\title{
Geriatric dyspnea: doing worse, feeling better
}

Sibylle Petersen, $\mathrm{PhD}^{1}$, Andreas von Leupoldt, $\mathrm{PhD}^{1}$, Omer van den Bergh, $\mathrm{PhD}^{1}$

${ }^{1} \mathrm{KU}$ Leuven, Research Group on Health Psychology, Tiensestraat 102, 3000 Leuven, Belgium

Corresponding author address: Sibylle Petersen, Research Group on Health Psychology, KU Leuven, Tiensestraat 102, 3000 Leuven, Belgium, sibylle.petersen@psy.kuleuven.be, phone: $0032-16326058$ 


\section{Table of Content}

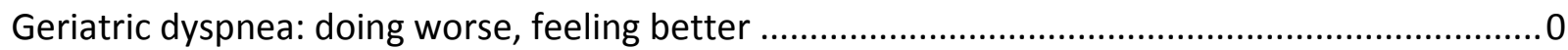

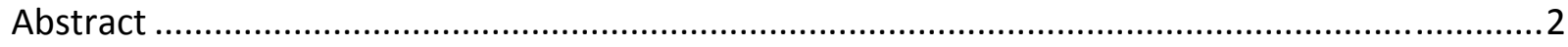

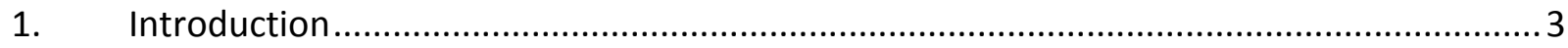

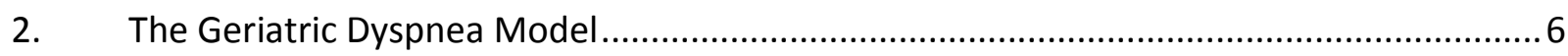

2.1. Age-related differences in perception and report of dyspnea .................................6

2.2. Peripheral pathways between age and dyspnea .................................................. 8

2.3. Central pathways between age and dyspnea ....................................................... 10

2.4. Motivation and strategies for emotion regulation in older age ................................11

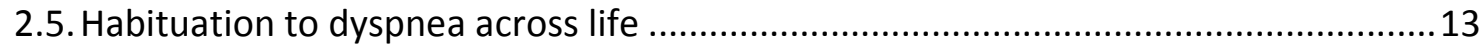

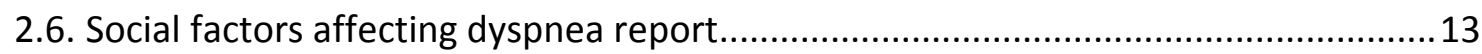

2.7. Comorbidities influencing dyspnea in older age ..................................................... 15

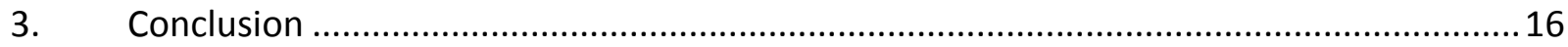

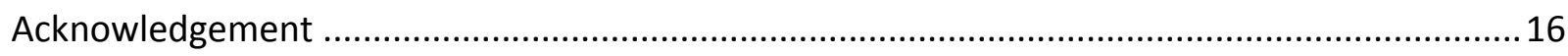

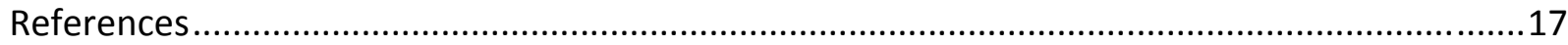

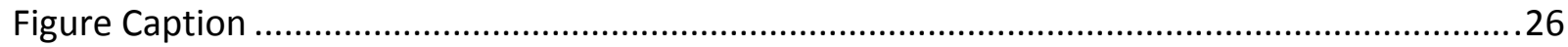




\begin{abstract}
Older age is associated with a decline in physical fitness and reduced efficiency of the respiratory system. Paradoxically, it is also related to reduced report of dyspnea, that is, the experience of difficult and uncomfortable breathing. Reduced symptom reporting contributes to misdiagnosis or late diagnosis of underlying disease, suboptimal treatment, faster disease progression, shorter life expectancy, lower quality of life for patients, and considerably increased costs for the health care system in an aging society. However, pathways in the complex relationship between dyspnea and age are not well explored yet.

We propose a model on geriatric dyspnea that integrates physiological, neurological, psychological and social pathways which link older age with dyspnea perception and expression. We suggest that the paradox of reduction of dyspnea in older age, despite physiological decline, can be solved by taking age-related changes on these multiple levels into account. In identifying these variables, the Geriatric Dyspnea Model highlights risk factors for reduced dyspnea perception and report in older age and pathways for intervention.
\end{abstract}

Key words: Age, ageing, dyspnea, breathlessness, interoception, emotion regulation 


\section{Introduction}

Dyspnea (the experience of difficult and uncomfortable breathing) is an excruciating, key symptom in many chronic and acute conditions such as cardiovascular, neuromuscular and respiratory diseases, late stage cancer, or psychological disorders such as panic disorder. About $25 \%$ of the general population and $50 \%$ of patients admitted to emergency departments are affected (Parshall et al., 2012). The American Thoracic Society defines dyspnea as a subjective experience which "derives from interactions among multiple physiological, psychological, social, and environmental factors, and may induce secondary physiological and behavioral responses" (ATS, 1999). Oftentimes, the self-report of dyspnea is poorly related to actual physiological changes and more strongly influenced by these bio-psychosocial factors (Petersen et al., 2011). In this respect, dyspnea is similar to pain and other subjective experiences of bodily dysfunction.

Throughout the normal process of ageing, physical fitness and the strength of respiratory muscles decline, gas exchange becomes less efficient and, as a result, breathing becomes more difficult. These physiologically changes would be expected to exacerbate dyspnea. However, dyspnea seems to be paradoxically reduced in older age (Silvestri \& Mahler, 1993). A similar relationship between reduced symptom reporting and older age has been also observed with pain (Gibson \& Farrell, 2004). The term "geriatric pain" (Melding, 1991, p. 249) was coined to emphasize that pain in older age differs both qualitatively and quantitatively from pain in younger age (Gagliese, 2009). Nevertheless, physiological and psychological processes underlying altered perception of pain or dyspnea in older age are poorly understood, and studies on pain sensitivity and ageing report inconsistent results (Yezierski, 2013). 
It might be adaptive for psychological well-being to be able to ignore inevitable physical nuisance such as dyspnea related to ageing in the absence of disease. However, ignoring perception of bodily alarm signals, such as impaired breathing, may also lead to delays in seeking medical assistance in the case of illness. Reduced report poses a barrier for optimal diagnostics and treatment since dyspnea, as subjective experience, cannot be measured other than by self-report (Parshall et al., 2012).

The severe problem of under-diagnosis and under-treatment in older age has been recognized in pain research (Gagliese, 2009). Guidelines for research and clinical practice have been developed to address pain in elderly individuals (AGS Panel on Chronic Pain in Older Persons, 1998), and the International Year of Pain in Older Persons (2006-2007) has raised awareness with health care professionals and the broader public (Gibson, 2007). Dyspnea in older age has received considerable less attention despite population-based studies reporting dramatic rates of under-diagnosis. Under-report contributes to under-diagnosis in Chronic Obstructive Pulmonary Disease (COPD) with about one third of older individuals with clinically relevant airflow limitation not reporting any symptoms (Bednarek, et al., 2008). Only $9.4 \%$ to $22 \%$ of older individuals with clinically relevant airflow limitations are diagnosed with COPD and treated (Bednarek et al., 2008; Pena et al., 2000). Also in older patients with asthma, airflow restrictions are often poorly perceived and not optimally treated (de Vries \& Petermann, 2008; Parameswaran et al., 1998). In COPD and asthma, under-reporting, late diagnosis or misdiagnosis, and poor treatment are related to mortality (de Vries \& Petermann, 2008; Bednarek, et al., 2008).

In exploring the causes underlying these difficulties in reporting and diagnosing dyspnea, we will review literature on physiological, psychological, and social changes in older age that 
might act as pathways between older age and dyspnea perception and report. These paths are summarized in Figure 1. In this Geriatric Dyspnea Model, the first pathway is peripheral processing. We will outline in the following how peripheral processes might decrease (or increase) dyspnea sensitivity in older age. The second pathway targets central processes of dyspnea perception and related psychological processes of regulating distress associated with dyspnea. As a third pathway, we suggest that social factors might affect self-report of dyspnea in older age independent of changes in perception. Furthermore, effects of co-morbid conditions which might overrule or increase age-related effects on dyspnea perception and report will be discussed.

The model is a working model based on current empirical research and theory. It aims to identify questions for research and clinical practice. Importantly, the model is not a unidirectional one. More frequent experience of dyspnea may in turn affect physiological, neurological, psychological and social processes as well as comorbid conditions. Furthermore, based on the current literature, the Geriatric Dyspnea Model is a model on dyspnea in older age and not a model on the effects of ageing on dyspnea. Longitudinal studies on dyspnea perception and report are scarce and only cover short time spans of 2-5 years in an already older population (Hardie et al., 2005; Mahler et al., 2012; Oga et al., 2007, see below). Additional factors that might influence the relationship of older age and dyspnea such as gender will be discussed. 


\section{The Geriatric Dyspnea Model}

\subsection{Age-related differences in perception and report of dyspnea}

Dyspnea is a multidimensional sensation with at least three main qualities. These are breathing effort, chest tightness, and air hunger (e.g. Petersen et al., 2008; Meek et al., 2012). The experience of these different qualities is related to processing of information from different afferent systems which include the respiratory muscles (feeling of breathing effort), intrapulmonary receptors (chest tightness) and peripheral or central chemoreceptors (feelings of air hunger and suffocation) (Parshall et al., 2012). Interestingly, despite these different afferent systems, the different qualities of dyspnea seem to be similarly affected by older age.

Studies testing age-effects on the perception of breathing effort found that older asthma patients as well as older healthy individuals have higher detection thresholds for external respiratory loads (inducing respiratory effort) than younger healthy individuals and asthma patients (Allen et al., 2009; 2012; Altose et al., 1985; Tack et al., 1981; 1982; 1983). Moreover, older asthma patients report less obstruction and less chest tightness in response to methacholine-induced bronchoconstriction (Connolly et al., 1992). These findings are particularly interesting since older individuals require lower methacholine doses to induce a clinically relevant, $20 \%$ drop in lung function and take longer to recover after receiving medication to reduce bronchoconstriction (Connolly et al., 1995). Furthermore, several studies report reduced response to $\mathrm{CO}_{2}$ rebreathing (inducing air hunger) in healthy older individuals, which indicates higher vulnerability for a delay in registering increasing $\mathrm{CO}_{2}$ levels (e.g., Brischetto et al., 1984; Marsden et al. 2012). Patients with COPD, which is typically diagnosed in later life, typically show hypercapnia (increased arterial $\mathrm{CO}_{2}$

levels) at rest but still report little or no air hunger (Mahler et al., 2003). These studies suggest that 
peripheral physiological processes in age-related changes in the perception of dyspnea are complex and affect multiple afferent systems.

The clinical experience of dyspnea is more complex than the experience of difficult breathing induced in the laboratory (Lansing et al., 2009). However, clinical studies suggest that symptom report in asthma (Battaglia et al., 2005; Parameswaran et al., 1998) and pneumonia (Metlay et al., 1997 ) is reduced in older compared to younger age. In chronic heart failure, older patients reported less dyspnea compared to younger patients after a standardized six minute walking test (6 MWT) (Riegel et al., 2010). Older patients with COPD also reported less dyspnea directly after a 6 MWT and retrospectively less dyspnea in daily life (age differences were moderated by patients' anxiety levels, Petersen et al., submitted). However, other studies found no consistent effect of age on dyspnea report during exercise (Kilian et al., 1992; Mahler et al., 2003; Wilkie et al., 2012).

A limited number of longitudinal studies have been conducted to examine dyspnea perception across older age. Two studies suggested that report of dyspnea increase in COPD patients independent of reduced lung function (Mahler et al., 2012; Oga et al., 2007). However, while retrospective report in the study by Oga et al. (2007) was positively related to age, age was also related to substantially reduced dyspnea ratings after exercise testing in the same patients in a cross-sectional test. Furthermore, a five-year population based study indicated that dyspnea increases with older age, but decreases in very old age (>89 years; Hardie et al., 2005).

To summarize, the majority of experimental and cross-sectional studies evince a decrease in dyspnea in older age, but longitudinal assessments have noted increases in dyspnea over time. However, such inconsistencies between cross-sectional and longitudinal studies are to be expected, since these two types of studies target two different variables, age and ageing. Age effects are a 
cohort or generation effects that are related to a variety of psychological, social, and sociological factors. Effects of ageing are within-individual effects that are free of cohort effects and may be more closely related to individual physiological decline. Furthermore, the use of different methodologies in the two types of studies (retrospective self-report versus self-report during dyspnea induction) might further increase differences between these approaches. The majority of studies comparing age groups find reduced dyspnea perception and report in older age. As outlined above, the model proposed here is a model on dyspnea in older age and not on ageing. In the following, we will integrate findings from different disciplines such as respiratory medicine, neurology, psychology, and sociology to outline important moderators and mediators in the association of older age and dyspnea.

\subsection{Peripheral pathways between age and dyspnea}

Age-related decline of the respiratory system, in the absence of disease, is substantial (for reviews, see e.g., Mahler et al., 2003; Jensen et al., 2009). In the normal process of ageing, respiratory resistance increases (Niewoehner \& Kleinerman, 1974), and respiratory muscle strength decreases (Tolep \& Kelsen, 1993). Moreover, lung elasticity declines and stiffness of the chest wall increases (Mahler et al., 2003) contributing to a reduction in lung function starting as early as 20 years of age (Whaba, 1983). The average reduction in lung function until the age of 70 years is about $20 \%$ (ibid.). This decline can be more pronounced in patients with respiratory disease or in individuals who are exposed to smoke, dust, and/or chemicals at the work place and at home (Jones et al., 2012). Moreover, efficiency in gas exchange decreases in older age even in healthy non-smokers due to the shrinkage and loss of lung tissue as well as loss of elasticity (Mahler et al., 2003). In response to these changes, respiratory reserves in older 
individuals are reduced and ventilatory response to exercise is increased. This can occur despite maintained general fitness and preserved strength of muscles other than the respiratory muscles Brischetto et al., 1984).

The seemingly paradoxical reduction in dyspnea despite reduced efficiency of the respiratory system might be explained by be age-related functional and anatomical changes that reduced sensory sensitivity. Age-related decline in the number of peripheral receptors and afferents can result from tissue shrinkage and loss of fibers as it has been found to influence multiple sensory modalities like hearing, taste, smell, vision, touch, and pain (Riley et al., 2000; Yezierski, 2013). In addition, age-related changes in the serotonergic system have been reported, a system which plays an important role in the control of breathing (Behan et al., 2002). These changes have been associated with increased prevalence of obstructive sleep apnea in older age (ibid). However, pain research indicates that while we find an age-related reduction of the number of receptors and afferents (Gibson \& Farrell, 2004), other processes such as increased inflammatory levels can also increase pain sensitivity in older age (Yezierski, 2013). A similar level of complexity might be assumed for age-related effects on dyspnea. Ageing is associated with low-grade systemic inflammation (Vasto et al., 2009) which, in turn, is related to a reduction in lung function (Fabbri \& Rabe, 2007). The diverse effects of ageing on the respiratory system are likely to interact and create a complex system of interacting processes that has yet to be tested. In addition, differential effects of ageing on dyspnea in men and women will be an important topic for future research. For instance, there are protective hormonal effects in woman that reduced age effects on the physiology of the respiratory system until menopause (Becklake \& Kauffmann, 1999; Behan et al., 2002; Ofir et al., 2008). 


\subsection{Central pathways between age and dyspnea}

Very little is known on central processing of dyspnea in older age. We are aware of only one study which has tested age differences in respiratory-related evoked potentials (RREP, Harver et al., 1995). This study found reduced amplitude of RREPs in older compared to younger age and these age differences were more pronounced in later cognition-related components of RREPs. However, considerably more is known on central pathways in emotion regulation in older age. Inferences may be made from this research about the regulation of distress during dyspnea.

Neural networks that integrate information from respiratory-related afferent systems are very similar to those integrating pain-related information and these are often closely related or overlapping with networks involved in the processing of affect and the regulation of attention (Evans et al., 2010). Interestingly, some structures involved in the regulation of attention and emotion and the regulation of dyspnea and pain (e.g. left medial prefrontal cortex and the ventral ACC) seem largely unaffected by normal ageing. In contrast, other prefrontal areas that are related to cognitive functions show consistent age-related cortical loss and reduced activation during cognitive tasks (for a review, see e.g., Fjell et al., 2009¹). Thus, during normal ageing, there is a reduction in neuro-cognitive capacities but not necessarily in neurological emotion regulation capacities. Three out of six cross-sectional studies in a current review go so far as to suggest a thickening of these regions in older age and the potential for enhanced affective capacities (Fjell et al., 2009). Age range of participants in studies included in this review was $18-94$ years. These results suggest that during healthy ageing emotion regulation capacities are not necessarily affected but might even increase (Mather, 2012). Regulation of the distress component of dyspnea might

\footnotetext{
${ }^{1}$ but see also a review on cortical gain in older age by practicing cognitive tasks, meditation and physical exercise, Lustig et al., 2009
} 
also remain intact or potentially improve. Furthermore, age-related changes in regulation strategies and increased motivation to regulate distress may help to optimize the use of brain capacities (see below).

\subsection{Motivation and strategies for emotion regulation in older age}

Motivation for emotion regulation increases and regulation strategies become more fine-tuned in later life (Mather, 2012). From childhood to older age, there is a continuous shift towards less activation in the amygdala and greater activation of the prefrontal cortex when confronted with negative affective stimuli (Fischer et al., 2010). This shift in activation is associated with reduced expression of emotions and has been interpreted as shift towards higher motivation to regulate (negative) affect in older age (Mather, 2012). This motivation hypothesis is supported by studies which show that voluntary emotion regulation also leads to reduction in amygdala activity independent of age (Schaefer et al., 2002).

A growing body of literature provides evidence that older individuals who maintain psychological well-being throughout the process of ageing tend to show positivity effects. That is, they tend to pay more attention to positive information as opposed to negative information and sustain attention for positive information longer than younger individuals (for reviews, see Mater, 2012; Reed et al., 2012). Older individuals are more likely to withdraw from negative situations either by leaving the situation or withdrawing their attention (Reed et al., 2012). Furthermore, older age is related to decreases in rumination about negative events (Sütterlin et al., 2012). While younger individuals direct their attention to stimuli which are congruent with their mood, older individuals avoid attention towards negative stimuli even if they are in a negative mood (Isaacowitz et al., 2008). These behavioral and attentional preferences have enhanced memory 
effects for positive information (Mather, 2012; Reed et al., 2012). These studies support Response Shift Theory (e.g., Schwartz \& Spranger, 1999) which proposes that older individuals or patients with chronic disease maintain a high quality of life by shifting evaluation standards. Something once regarded as a considerable physiological alarm signal in younger age might become a wellknown minor nuisance in older age in comparison to general reduced levels of functioning. Social comparison can also support this response-shift, for example, comparison with others who have a higher symptom burden can lead to a more positive evaluation of personal health (Petersen et al., 2012; Petersen \& Ritz, 2010).

In addition to positivity effects, self-reported suppression of emotions also increases in older age particularly in women (Nolen-Hoeksema \& Aldo, 2011). Furthermore, stoic attitudes, that is, recognizing adversity (i.e., not suppressing it), but not allowing it to guide emotions or behavior have been described as a coping strategy in older patients suffering from chronic pain (Helme \& Gibson, 1999). Stoicism as an attitude towards dyspnea has yet to be explored, but similarities between pain and dyspnea suggest that they may also reduce report of dyspnea.

To summarize, in older age, capacities for affective regulation of dyspnea remain intact and might even increase. Furthermore, the motivation to regulate negative affect or avoid negative experiences increases in later life. Finally, strategies for redirecting attention and regulating emotion become more fine-tuned and successful. However, there is a dearth of research which examines whether negative physical stimulation (e.g. pain and dyspnea) is avoided as much as negative emotions in old age. Furthermore, we are unaware of studies testing whether attention towards unavoidable negative bodily stimulation is reduced in later life. Furthermore, we are unaware of 
studies examining whether the processing, storage, and retrieval of related content in memory is impaired in a similar way as for emotional content unrelated to bodily sensations.

\subsection{Habituation to dyspnea across life}

Habituation refers to reduced responding across repeated presentation of a stimulus. This has been found in response to $\mathrm{CO}_{2}$ rebreathing in the laboratory in healthy younger individuals (Wan et al., 2009). Another study with younger volunteers found that after repeated presentations of short respiratory occlusions, the amplitudes of later components related RREPs decreased. This reduction was paralleled with reduced magnitude ratings (Von Leupoldt et al., 2011). Results of a clinical study with older individuals also showed that repeated exposition to dyspnea by exercise training (paired with psychological intervention) can successfully reduce dyspnea-related distress in COPD patients (Carrieri-Kohlman et al., 1993). However, we are not aware of longitudinal studies exploring the development of blunted dyspnea perception in patient populations over longer periods of time. As in pain, exposure to chronically high dyspnea without pharmacological and psychological intervention can be assumed to be more likely to lead to sensitization than to habituation, particularly if symptom-related negative affect is high (Wan et al., 2012).

\subsection{Social factors affecting dyspnea report}

Numerous social barriers may affect the ability, opportunity, and/or motivation to report dyspnea independent of perception. Health literacy is one example for such a factor. Individuals with a poor access to or understanding of health-related information have difficulties to find their way into the increasingly complex health care system (Sudore et al., 2006). In addition they typically lack the communicative skills necessary to give accurate details on their symptoms and 
needs. Depending on the health care institution, $26-60 \%$ of patients across age groups have difficulties in understanding medical advice (Williams et al., 1995). Health literacy is lower in older individuals and especially those from low socio-economic status backgrounds. One might suggest that this is due to age-related cognitive impairment such as dementia. However, the relationship of age and health literacy holds also for older individuals without cognitive disabilities (Sudore et al., 2006).

Retirement is often related to a substantial loss of income and a chronic disease may be perceived as a substantial financial burden for the family and a threat to personal independence. The financial burden associated with chronic disease might therefore lead one to perceive fiscal costs as worse than the illness itself (Murray \& Callahan, 2003). Older individuals may consequentially avoid entering the health care system as long as symptoms are tolerable. Also, the stigma associated with chronic disease (i.e., that it is socially not desirable to complain about discomfort) might lead patients to wait until symptom burden is substantial.

Another social factor reducing opportunity and motivation to report symptoms might by loneliness. Depending on country (and measurement instrument) $20-40 \%$ of older individuals in Western societies feel lonely (Luo et al., 2012). Loneliness refers to the subjective experience of reduced social connectedness. Even if individuals are not socially isolated, this subjective experience of loneliness is related to lack of trust in others (Hawkley \& Cacioppo, 2010) and to reduced recruitment of social support (Hörchner et al., 2002). Lack of trust and lack of social support might delay symptom report until symptom burden becomes substantial.

These present just some examples to illustrate how social barriers that are typically experienced in later life might contribute to reduced self-report of dyspnea. These barriers need 
to be analyzed carefully to design interventions that will meet needs of older individuals, and to provide opportunity and encouragement for help seeking in this age group.

\subsection{Comorbidities influencing dyspnea in older age}

Half of the population older than 65 years has at least three chronic conditions requiring medical attention (Boyd et al., 2005). However, little is known on the effect of comorbid conditions on dyspnea. One important barrier to symptom report in older age is dementia, but next to nothing is known on how this affects the processing of dyspnea. Moreover, little is known on the reliability of assessment instruments for dyspnea in individuals with cognitive deficits. So far, only one scale has been developed to measure dyspnea in individuals unable to provide self-report (Campbell et al., 2010).

Furthermore, some studies suggest that chronic pain over time can lead to structural and functional changes in the brain independent from normal age-related changes (Apkarian et al., 2004). Little is known on how such changes might affect dyspnea perception in older age and contribute to sensitization or habituation. There is a similar lack of research investigating the relationship between age and the effect of opiates on pain and dyspnea. Research suggests that gender differences in the effect of opiates and antidepressants are moderated by age (Dahan et al., 2008). Age also moderates gender differences regarding the effects of opiates and antidepressants on the respiratory system, but systematic research is missing (ibid.).

Further contributing to a more complex picture of dyspnea experience in older age are psychological disorders. Depression is highly prevalent in chronic respiratory disease (Maurer et al., 2008) and can alter brain structure and brain metabolism (Savitz \& Drevets, 2009). How this might affect central processing of dyspnea is not known. 


\section{Conclusion}

The relationship between age and dyspnea is complex. Testing the simple association of age and dyspnea may be less informative than identifying pathways that determine direction and strength of this relationship. The Geriatric Dyspnea Model is a working model that aims at identifying questions for research and clinical practice by integrating findings on physiological, neurological, psychological, and social changes which may (directly and/or indirectly) affect perception and report of dyspnea particularly in older age. Only if underlying processes are identified, individuals at high risk for reduced perception and report of clinically relevant symptoms can be identified. Furthermore, the closer interventions are tailored to underlying processes the more effective they will be.

\section{Acknowledgement}

This work was supported by a fellowship of the Research Foundation Flanders to the first author. 


\section{References}

AGS Panel on Chronic Pain in Older Persons, 1998. The management of chronic pain in older persons. J. Am. Geriatr. Soc. 44, 635-651.

Allen, S. C., \& Khattab A., 2012. The airflow resistance sensing threshold during tidal breathing rises in old age in patients with asthma. Age Ageing. 41, 557-560.

Allen, S. C., Vassallo, M., \& Khattab, A., 2009. The threshold for sensing airflow resistance during tidal breathing rises in old age: implications for elderly patients with obstructive airways diseases. Age Ageing. 38, 548-552.

Altose, M. D., Leitner, J., \& Cherniack, N. S., 1985. Effect of age and respiratory efforts on the perception of resistive ventilatory loads. J. Gerontol. 40, 147-153.

American Thoracic Society, 1999. Dyspnea: mechanisms, assessment, and management. A consensus statement. Am. J. Respir. Crit. Care. Med. 159, 321-340.

Battaglia, S., Sandrini, M. C., Catalano, F., Arcoleo, G., Giardini, G., Vergani, C., \& Bellia, V., 2005. Effects of aging on sensation of dyspnea and health-related quality of life in elderly asthmatics. Aging Clin. Exp. Res. 17, 287-292.

Becklake, M. R., \& Kauffmann, F., 1999. Gender differences in airway behaviour over the human life span. Thorax, 54. 1119-1138.

Bednarek, M., Maciejewski, J., Wozniak, M., Kuca, P., \& Zielinski, J., 2008. Prevalence, severity and underdiagnosis of COPD in the primary care setting. Thorax. 63, 402-407.

Behan, M., Zabka, A. G., \& Mitchell, G. S., 2002. Age and gender effects on serotonin-dependent plasticity in respiratory motor control. Respir. Physiol. Neurobiol. 131, 65-77. 
Boyd, C. M., Darer, J., Boult, C., Fried, L. P., Boult, L., \& Wu, A. W., 2005. Clinical practice guidelines and quality of care for older patients with multiple comorbid diseases: implications for pay for performance. JAMA, 294, 716-724.

Brischetto, M. J., Millman, R. P., Peterson, D. D., Silage, D. A., \& Pack, A. I., 1984. Effect of aging on ventilatory response to exercise and CO2. J. Appl. Physiol., 56, 1143-1150.

Campbell, M. L., Templin, T., \& Walch, J. A., 2010. Respiratory Distress Observation Scale for patients unable to self-report dyspnea. J. Palliat. Med., 13, 285-290.

Carrieri-Kohlman, V., Douglas, M. K., Gormley, J. M., \& Stulbarg, M.S., 1993. Desensitization and guided mastery: treatment approaches for the management of dyspnea. Heart Lung, 22, 226-234.

Connolly, M. J., Crowley, J. J., Charan, N. B., Nielson, C. P., \& Vestal, R. E., 1992. Reduced subjective awareness of bronchoconstriction provoked by methacholine in elderly asthmatic and normal subjects as measured on a simple awareness scale. Thorax, 47, 410-413.

Connolly, M. J., Crowley, J. J., Charan, N. B., Nielson, C. P., \& Vestal, R. E., 1995. Impaired bronchodilator response to albuterol in healthy elderly men and women. Chest, 108, 401-406.

Dahan, A., Kest, B., Waxman, A. R., \& Sarton, E., 2008. Sex-specific responses to opiates: animal and human studies. Anesth. Analg., 107, 83-95.

de Vries, U., \& Petermann, F., 2008. Asthma among senior adults. Internist, 49, 1335-1338.

Evans, K. C., 2010. Cortico-limbic circuitry and the airways: Insights from functional neuroimaging of respiratory afferents and efferents. Biol. Psychol., 84, 13-25. 
Fabbri, L. M., \& Rabe, K. F. 2007. From COPD to chronic systemic inflammatory syndrome? Lancet, 370, 797-799.

Fischer, H., Nyberg, L., \& Bäckman, L., 2010. Age-related differences in brain regions supporting successful encoding of emotional faces. Cortex, 46, 490-497.

Fjell, A. M., Westlye, L. T., Amlien, I., Espeseth, T., Reinvang, I., Raz, N., Agartz, I., Salat, D. H., Greve, D. N., Fischl, B., Dale, A. M., \& Walhovd, K. B. 2009. High consistency of regional cortical thinning in aging across multiple samples. Cereb. Cortex, 19, 2001-2012.

Gagliese, L., 2009. Pain and aging: the emergence of a new subfield of pain research. J. Pain, 10, 343-353.

Gibson, S. J., \& Farrell, M., 2004. A review of age differences in the neurophysiology of nociception and the perceptual experience of pain. Clin. J. Pain, 20, 227-239.

Gibson, S. J., 2007. IASP global year against pain in older persons: highlighting the current status and future perspectives in geriatric pain. Expert. Rev. Neurother. 7, 627-635.

Harver, A., Squires, N. K., Bloch-Salisbury, E., \& Katkin, E. S., 1995. Event-related potentials to airway occlusion in young and old subjects. Psychophysiol., 32, 121-129.

Hardie, J. A., Vollmer, W. M., Buist, A. S., Bakke, P., \& Mørkve, O., 2005. Respiratory symptoms and obstructive pulmonary disease in a population aged over 70 years. Respir. Med., 2005, 99, 186-195.

Hawkley, L. C., \& Cacioppo, J. T. 2010. Loneliness matters: a theoretical and empirical review of consequences and mechanisms. Ann. Behav. Med., 40, 218-227.

Helme, R. D. \& Gibson, S. J., 1999. Pain in older people. In: Crombie IK (ed.) Epidemiology of Pain. Seattle: IASP Press. 
Hörchner, R., Tuinebreijer, W. E., Kelder, H., \& van Urk, E., 2002. Coping behavior and loneliness among obese patients. Obes. Surg., 12, 864-868.

Isaacowitz, D. M., Wadlinger, H. A., Goren, D., \& Wilson, H. R., 2006. Selective preference in visual fixation away from negative images in old age? An eye-tracking study. Psychol. Aging, 21, 40-48.

Jensen, D., Ofir, D., \& O'Donnell, D. E., 2009. Effects of pregnancy, obesity and aging on the intensity of perceived breathlessness during exercise in healthy humans. Respir. Physiol. Neurobiol., 167, 87-100.

Jones, P., Miravitlles, M., van der Molen, T., Kulich, K., 2012. Beyond FEV F $_{1}$ in COPD: a review of patient-reported outcomes and their measurement. Int. J. Chron. Obstruct. Pulmon. Dis., 7, 697-709.

Luo, Y., Hawkley, L. C., Waite, L. J., \& Cacioppo, J. T., 2012. Loneliness, health, and mortality in old age: a national longitudinal study. Soc. Sci. Med., 74, 907-914.

Lustig, C., Shah, P., Seidler, R., \& Reuter-Lorenz, P. A., 2009. Aging, training, and the brain: a review and future directions. Neuropsychol. Rev., 19, 504-522.

Mahler, D. A., Fierro-Carrion, G., \& Baird, J. C., 2003. Evaluation of dyspnea in the elderly. Clin. Geriatr. Med., 19, 19-33.

Mahler, D. A., Ward, J., Waterman, L. A., \& Baird, J. C. 2012. Longitudinal changes inpatientreported dyspnea in patients with COPD. COPD, 9, 522-527.

Marsden, K. R., Haykowsky, M. J., Smirl, J. D., Jones, H., Nelson, M. D., Altamirano-Diaz, L. A., Gelinas, J. C., Tzeng, Y. C., Smith, K. J., Willie, C. K., Bailey, D. M., \& Ainslie, P. N., 2012. 
Aging blunts hyperventilation-induced hypocapnia and reduction in cerebral blood flow velocity during maximal exercise. Age (Dordr.), 2012, 34, 725-735.

Mather, M. 2012. The emotion paradox in the aging brain. Ann. N. Y. Acad. Sci., 1251, 33-49. Maurer, J., Rebbapragada, V., Borson, S., et al., 2008. Anxiety and depression in COPD: current understanding, unanswered questions, and research needs. Chest, 134, 43S-56S.

Meek, P. M., Banzett, R., Parshall, M. B., Gracely, R. H., Schwartzstein, R. M., \& Lansing, R., 2012. Reliability and validity of the multidimensional dyspnea profile. Chest, 141, 1546-1553. Apkarian, A. V., Sosa, Y., Sonty, S., Levy, R. M., Harden, R. N., Parrish, T. B., \& Gitelman, D. R., 2004. Chronic back pain is associated with decreased prefrontal and thalamic gray matter density. J. Neurosci., 24, 10410-10415.

Melding, P. S., 1991. Is there such a thing as geriatric pain? Pain, 46, 119-121.

Metlay, J. P., Schulz, R., Li, Y. H., Singer, D. E., Marrie, T. J., Coley, C. M., Hough, L. J., Obrosky, D. S., Kapoor, W. N., \& Fine, M. J., 1997. Influence of age on symptoms at presentation in patients with community-acquired pneumonia. Arch. Intern. Med., 157, 1453-1459.

Murray, M. D., \& Callahan, C. M., 2003. Improving medication use for older adults: an integrated research agenda. Ann. Intern. Med., 139, 425-429.

Nolen-Hoeksema, S., \& Aldao, A., 2011. Gender and age differences in emotion regulation strategies and their relationship to depressive symptoms. Pers. Indv. Diffs., 51,704-708. Oga, T., Nishimura, K., Tsukino, M., Sato, S., Hajiro, T., \& Mishima, M., 2007. Longitudinal deteriorations in patient reported outcomes in patients with COPD. Respir. Med., 101, 146-153. 
Parameswaran, K., Hildreth, A. J., Chadha, D., Keaney, N. P., Taylor, I. K., \& Bansal, S. K., 1998. Asthma in the elderly: underperceived, underdiagnosed and undertreated; a communitysurvey. Respir. Med., 92, 573-577.

Parshall, M. B., Schwartzstein, R. M., Adams, L., Banzett, R. B., Manning, H. L., Bourbeau, J., Calverley, P. M., Gift, A. G., Harver, A., Lareau, S. C., Mahler, D. A., Meek, P. M., \& O'Donnell, D. E., 2012. American Thoracic Society Committee on Dyspnea. An official American Thoracic Society statement: update on the mechanisms, assessment, and management of dyspnea. Am. J. Respir. Crit. Care. Med., 185, 435-452.

Pena, V. S., Miravitlles, M., Gabriel, R., Jiménez-Ruiz, C. A., Villasante, C., Masa, J. F., Viejo, J. L., \& Fernández-Fau, L., 2000. Geographic variations in prevalence and underdiagnosis of COPD: results of the IBERPOC multicentre epidemiological study. Chest, 118, 981-989.

Petersen, S., \& Ritz, T., 2010. Dependency of illness evaluation on the social comparison context: findings with implicit measures of affective evaluation of asthma. Br. J. Health Psychol., $15,401-416$

Petersen, S., Orth, B., \& Ritz, T. 2008. Awareness of breathing: The structure of language descriptors of respiratory sensations. Health. Psychol., 27, 122-127.

Petersen, S., Taube, K., Lehmann, K., Van den Bergh, O., \& von Leupoldt., 2012. Social comparison and anxious mood in pulmonary rehabilitation: The role of cognitive focus. Br. J. Health Psychol., 17, 463-476.

Petersen, S., Taube, K., Lehmann, K., Van den Bergh, O., Magnussen, H., \& von Leupoldt. submitted. Age, Anxiety and Dyspnea in COPD. 
Petersen, S., van den Berg, R., Janssens, T., \& Van den Bergh, O., 2011. Illness and symptom perception: a theoretical approach towards an integrative measurement model. Clin. Psychol. Rev., 31, 428-439.

Reed, A. E., \& Carstensen, L. L. 2012. The theory behind the age-related positivity effect. Front. Psychol., 3, 339.

Riegel, B., Dickson, V. V., Cameron, J., Johnson, J. C., Bunker, S., Page, K., \& Worrall-Carter, L. Symptom recognition in elders with heart failure. J. Nurs. Scholarsh., 42, 92-100.

Riley, J. L., III, Wade, J. B., Robinson, M. E., \& Price, D. D., 2001. The stages of pain processing across the adult lifespan. J. Pain, 1, 162-170.

Savitz, J., \& Drevets, W. C., 2009. Bipolar and major depressive disorder: neuroimaging the developmental-degenerative divide. Neurosci. Biobehav. Rev., 33, 699-771.

Schwartz, C. E., \& Sprangers, M. A., 1999. Methodological approaches for assessing response shift in longitudinal health-related quality-of-life research. Soc. Sci. Med., 48, 1531-148.

Schaefer, S. M., Jackson, D. C., Davidson, R. J., Aguirre, G. K., Kimberg, D. Y., \& Thompson-Schill, S. L., 2002. Modulation of amygdalar activity by the conscious regulation of negative emotion. J. Cogn. Neurosci., 14, 913-921.

Silvestri, G. A., \& Mahler, D. A., 1993. Evaluation of dyspnea in the elderly patient. Clin. Chest. Med., 14, 393-404.

Sudore, R. L., Mehta, K. M., Simonsick, E. M., Harris, T. B., Newman, A. B., Satterfield, S., Rosano, C., Rooks, R. N., Rubin, S. M., Ayonayon, H. N., \& Yaffe, K., 2006. Limited literacy in older people and disparities in health and healthcare access. J. Am. Geriatr. Soc., 54, 770-776. Sütterlin, S., Paap, M., Babic, S., Kübler, A., \& Vögele, C. 2012. Rumination and age: Some things get better. J. Aging Res. 
Tack, M., Altose, M. D., \& Cherniack, N. S., 1981. Effect of aging on respiratory sensations produced by elastic loads. J. Appl. Physiol., 50,844-50.

Tack, M., Altose, M. D., \& Cherniack, N. S., 1982. Effect of aging on the perception of resistive ventilatory loads. Am. Rev. Respir. Dis., 126, 463-467.

Tack, M., Altose, M. D., \& Cherniack, N. S., 1983. Effects of aging on sensation of respiratory force and displacement. J. Appl. Physiol., 55, 1433-1440.

Ofir, D., Laveneziana, P.,Webb, K. A., Lam, Y. M., \& O'Donnell, D. E., 2008. Sex differences in the perceived intensity of breathlessness during exercise with advancing age. J. Appl. Physiol., 104, 1583-1593.

Tolep, K., \& Kelsen, S. G., 1993. Effect of aging on respiratory skeletal muscles. Clin. Chest Med., $14,363-378$.

Vasto, S., Carruba, G., Lio, D., Colonna-Romano, G., Di Bona, D., Candore, G., \& Caruso, C., 2009. Inflammation, ageing and cancer. Mech. Ageing Dev., 130, 40-45.

von Leupoldt, A., Brassen, S., Baumann, H. J., Klose, H., \& Büchel, C., 2011. Structural brain changes related to disease duration in patients with asthma. PLoS One, 6:e23739.

Wan, L., Van Diest, I., De Peuter, S., Bogaerts, K., \& Van den Bergh, O., 2009. Repeated breathlessness experiences induced by hypercapnia: differential effects on intensity and unpleasantness. Chest, 135, 455-461.

Wan, L., Stans, L., Bogaerts, K., Decramer, M. \& Van den Bergh, O., 2012. Sensitization in medically unexplained dyspnea: Differential effects on intensity and unpleasantness. Chest, 141, 989-995. 
Wahba, W. M., 1983. Influence of aging on lung function--clinical significance of changes from age twenty. Anesth. Analg., 62, 764-776.

Wilkie, S. S., Guenette, J. A., Dominelli, P. B., \& Sheel, A. W., 2012. Effects of an aging pulmonary system on expiratory flow limitation and dyspnoea during exercise in healthy women. Eur. J. Appl. Physiol., 112, 2195-2204.

Williams, M. V., Parker, R. M., Baker, D. W., Parikh, N. S., Pitkin, K., Coates, W. C., \& Nurss, J. R., 1995. Inadequate functional health literacy among patients at two public hospitals. JAMA, 274, 1677-1682.

Yezierski, R. P., 2012. The effects of age on pain sensitivity: preclinical studies. Pain Med., 13, S27-36. 


\section{Figure Caption}

Figure 1: The Geriatric Dyspnea Model on the relationship between older age and dyspnea perception and report. Plus and minus signs indicate hypotheses on the direction of influence. 


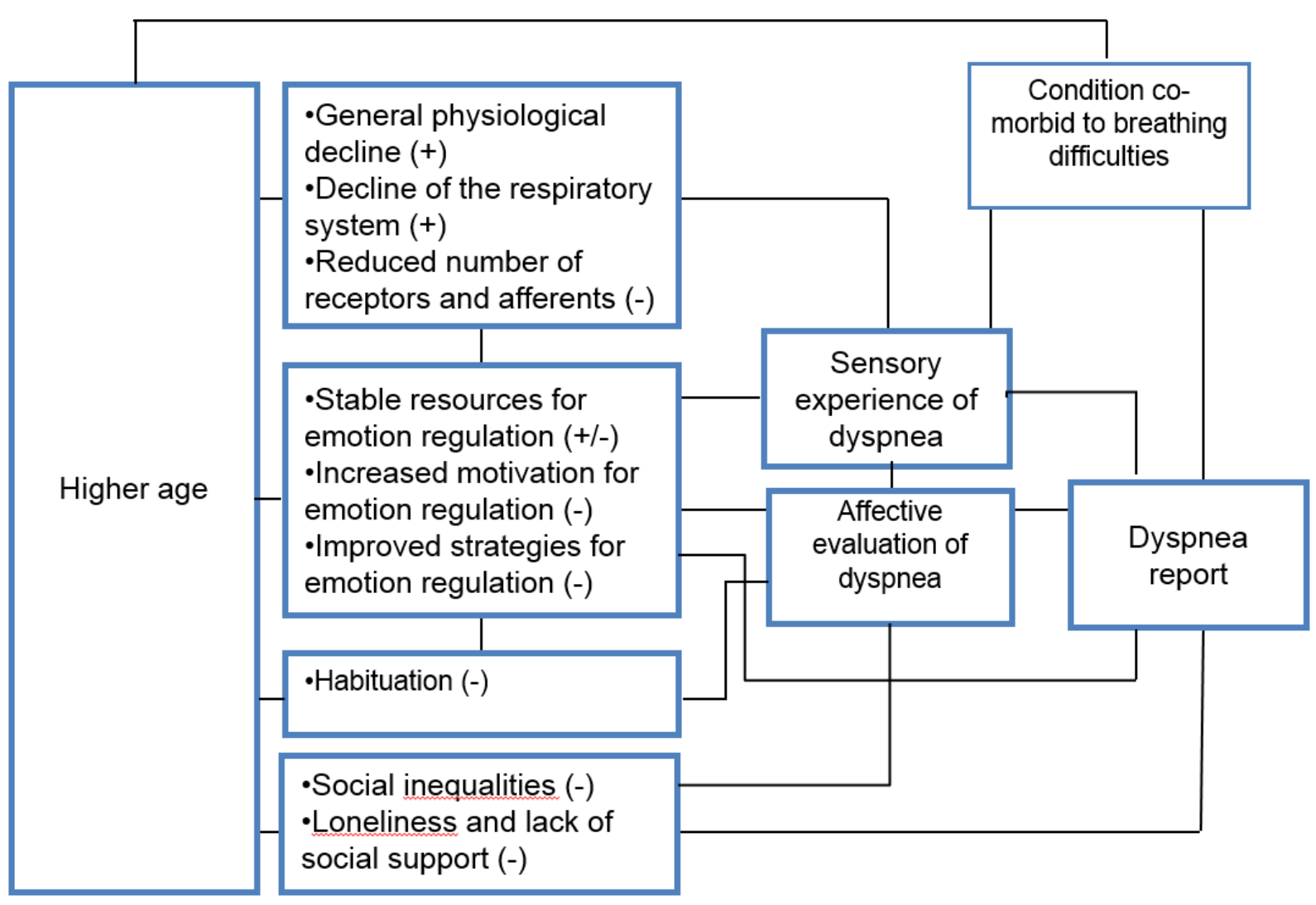

